TAPROBANICA, ISSN 1800-427X. January, 2015. Vol. 07, No. 01: pp. 14-19, pls. 9-11.

(C) Research Center for Climate Change, University of Indonesia, Depok, Indonesia \& Taprobanica Private Limited, Homagama, Sri Lanka

www.taprobanica.org

\title{
PREYING FREQUENCY OF COMMON KINGFISHER, Alcedo atthis (LINNAEUS, 1758) IN BANGLADESH
}

\author{
Habibon Naher* \\ *Department of Zoology, Jagannath University, Dhaka 1000, Bangladesh; E-mail: habibonnaher@yahoo.com
}

\begin{abstract}
A study on the preying frequency of common kingfisher (Alcedo atthis) was conducted from September 2008 to September 2011 at Nikunja-1 in Dhaka City Corporation Area of Bangladesh. The objective of the study was to determine the average preying frequency per day across different months using focal animal sampling method. It preyed 8.5 times / day, with the highest frequency of preying at 11:01-12:00 $\mathrm{h}$ and 16:01-17:00 $\mathrm{h}$. The average frequency was highest in September and lowest in April and highest in monsoon season and lowest in summer. Food items comprised of arthropods (31.7\%) and fish (68.3\%). From May through September, they avoided arthropods preferring fish as it was peak breeding season. During this period, they were preoccupied with courtship, nest building and caring of their nestlings.
\end{abstract}

Key words: breeding season, behaviour, Dhaka City, feeding activities, monsoon, summer.

\section{Introduction}

Among the 95 species of kingfishers worldwide (Sibley \& Monroe, 1993), 12 are found in Bangladesh (Husain, 1979; Islam, 2003; IUCN, 2000; Khan, 1982; Sarker \& Sarker, 1988; Siddiqui et al., 2008). The common kingfisher (Alcedo atthis) is a resident and common species found in Pakistan and the northern sub-continent including Nepal, Sikkim, Bhutan, Assam, and Manipur (Ali \& Ripley, 1983). A few studies have been conducted on the common kingfisher across the world (e.g. Heneberg, 2004; Kasahara \& Katoh, 2008; Melo \& Fuchs, 2008; Peris \& Rodriguez, 1997; Raven, 1986; Reynolds \& Hinge, 1996; Sayako et al., 2002), with some causal information on kingfishers of Bangladesh (Ahsan \& Saeed, 1990; Husain, 1979; Husain et al., 1983; Islam et al., 1999; Khan, 1982, 1986; Reza et al., 2003; Sarker, 1985, 1986, 1989). Except for these studies, no information is available about the kingfisher in Bangladesh. Hence, we studied the preying frequency of the common kingfisher per day in breeding and nonbreeding seasons from Sept. 2008 to Sept. 2011.

\section{Materials and Methods}

Study area: The study was carried out in Nikunja-1, Uttara, Dhaka, Bangladesh. This area is under the Dhaka City Corporation and on the 
west side of Dhaka Airport highway. There are two Lakes, one on the east (23 $49^{\prime} 14.81^{\prime \prime}-$ $23^{\circ} 49^{\prime} 36.04$ 'N, $\left.\quad 90^{\circ} 25^{\prime} 02.38^{\prime \prime}-90^{\circ} 25^{\prime} 12.30^{\prime \prime} \mathrm{E}\right)$ and the other on the west side $\left(23^{\circ} 49^{\prime} 26.33^{\prime \prime}-\right.$ $23^{\circ} 49^{\prime} 30.77$ 'N, 90²4'55.60"-90²4'59.82”E) of the Nikunja-1 residential area. The size of the eastern lake is $668.5 \times 17.07 \mathrm{~m}$ and western lake is $218.13 \times 75.05 \mathrm{~m}$. The northern and southern side of Nikunja-1 is surrounded by Nikunja-2 residential area and Dhaka Cantonment Golf field respectively.

Data collection and analysis: Preying frequency of the common kingfisher was observed at least once a week during the non-breeding season and three times a week during the breeding season. The birds were observed from 07:00 $\mathrm{h}$ to 19:00 $\mathrm{h}$ from May through September, from 07:00 $\mathrm{h}$ to 18:00 h in October, March and April, and from 07:30 $\mathrm{h}$ to $17: 30 \mathrm{~h}$ during November to February. The variation of time was due to the availability of day light in different months as the species is diurnal. Behavioural data were collected using the focal animal sampling technique of Altmann (1974). There were three 15-minute continuous monitoring periods in each hour followed by a 5-minute break. During each 15-minute period (block), only one bird was monitored. All important activities were recorded. A total of 1552 hours in 134 days were spent in the field and $465615 \mathrm{~min}$ monitoring periods were collected. The frequency of preying (number of dives into water or number of plunges in the air for successful or unsuccessful preying) for different food items by each individual was noted per block. Both immature and adult arthropods were preyed on. When they preyed upon larvae or nymph of arthropods they dove 22 to 49 times per feeding bout but when they preyed on adult arthropods or any fish item they dove one to seven times per feeding bout. The adult arthropods (may fly, water spider, dragon and damsel fly) were found to be flying in flock near water hyacinth during the afternoon when the kingfishers preyed upon them. The larvae, pupae and nymph of different arthropods (mosquito, dragon fly, damsel fly and may fly) were usually found in a mass. So it was not possible to calculate the preying frequency per larvae, pupae and nymph separately. Thus the preying frequencies of these items were counted together. When the bird was observed to dive continuously (22 to 49 times) in a specific area, the sample from that area was collected and examined by an entomologist. The adults of various arthropods and fish were identified immediately by direct observation with the help of a pair of binoculars and a telescope. During preying, photographs and video clips were taken which were used to identify the species if confusion arose. With the support of a senior entomologist arthropods were identified. The average preying frequencies per day, per hour and per month in a year, as well as during breeding and non-breeding seasons were calculated. To compare seasonal variation, the year was divided into three seasons: November to February as winter, March to June as summer and July to October as monsoon. Preying frequencies were analysed by Chi- square $(\chi 2)$ test.

\section{Results and Discussion}

Preying frequency $(\boldsymbol{n}=537)$ : The common kingfisher preyed on a number of different species and more than $70 \%$ of their attempts were successful $(n=407)$. It preyed on different species of food (8.5 times / day) of which fish were highly (5.8 times / day) preferred.

Preying at different day periods $(n=407)$ : The highest preying frequency was at 11:01-12:00 $\mathrm{h}$ and 16:01-17:00 h (Fig. 1), but differences in frequencies at different periods in the day were not statistically significant. The white-breasted kingfisher had a typically bimodal feeding pattern (Ali et al., 2010; Asokan, 1995; Evers, 1994; Natarajan, 1991; Ramachandran, 1998; Rodway, 1998; Sivakumaran \& Thiyagesan 2003). Feeding activity in the late evening may reflect their need for overnight energy requirements (Kelly, 1998).

Monthly preying frequency $(n=407)$ : The average frequency was the highest in September (Fig. 2) because in that month they raise their nestlings and trained them to prey on different foods. Thus during this period they needed more food compared with other months. The lowest frequency was observed in April as they were busy building their nests. However, the differences in monthly preying frequencies were not statistically significant.

Seasonal preying $(n=407)$ : The average preying frequency per day was the highest in monsoon and lowest in summer (Fig. 3). It was more or less related with the breeding season. Ali et al. (2010) reported that the scanning 
activity of Halcyon smyrnensis was greater in monsoon and post-monsoon periods when insects or other preys were abundant and lower in the summer when prey was in short supply at Cauvery Delta in Southern India. But it was more often during the summer when the food resources were generally abundant and less during the monsoon (Asokan et al., 2009) at Tamil Nadu in India. There were both successful and unsuccessful preying attempts. (Fig. 3). The summer recorded the highest number of successful attempts which could be due to the short supply food resources. However, average preying frequencies per day were not significantly different across seasons.

Prey on arthropods (n =129): Arthropods comprised $31.7 \%$ of prey. It was $83 \%$ for $H$. smyrnensis (Asokan et al., 2009). Preying frequency of arthropods varied at different periods in a day but it was not statistically significant. It was the highest at 10:01-11:00 $\mathrm{h}$ (Fig. 4). Preying frequency of arthropods significantly varied among months $\left(\chi^{2}=24.6\right.$, $\mathrm{df}=11, \mathrm{p}<0.05)$ (Fig. 5). In the month of May through September, they avoided preying on the arthropods during the peak breeding season whereby they concentrate on courtship, nest building and caring of their nestlings. It preyed on arthropods only from October to April while the highest rate of preying was in January. Preying frequency of arthropods significantly varied among season $\left(\chi^{2}=6.31, \mathrm{df}=2, \mathrm{p}<\right.$ 0.05) (Fig. 6). The highest was during winter because there is an abundance of them compared with other seasons. During winter, the water is calm and quiet and thus the number of arthropods increases in number without any natural disasters. Dhindsa \& Saini (1994) reported that birds stand supreme among vertebrates as enemies of insects because they are highly mobile and are able to congregate quickly in large numbers when sudden outbreaks of insect pests occur. During the rainy months, most of the larvae, pupae or nymphs of arthropods are washed away due to heavy rain or floodwater or adults are destroyed due to storm and strong wind. Asokan et al. (2009) recorded that during the rainy season (September to January) when the weather is much warmer and rivers and ponds are mostly inundated, $H$. smyrnensis feeds on aquatic animals such as fish and frogs, while during the drier months (February to August) they feed on mainly terrestrial animals in Tamil Nadu in South India.
It shows that preying on particular food items in particular season is similar between Tamil Nadu and Bangladesh.

Prey on fish $(n=278)$ : Fish comprised $68.3 \%$ of food resources for the kingfishers. It preyed 5.8 times per day on average. Preying frequency of fish varied at different day periods but it was not statistically significant. Fish were preyed on all through the day. There were three peaks (08:01-10:00 h, 11:01-13:00 $\mathrm{h}$ and 15:01-17:00 h) (Fig. 4). Highest frequency was during 09:0110:00 $\mathrm{h}$ when they were hungry after long overnight stay and 16:01-17:00 h for overnight energy requirements. No or little fish was preyed on at $1300-1500 \mathrm{~h}$ during their resting period. Preying frequency of fish varied monthly but it was not statistically significant. The preying frequency was found increasing from April through September (Fig. 5) because it was their breeding season. The average preying frequency per day varied in different seasons but it was not statistically significant. The highest frequency was during the monsoon (Fig. 6). It was related to the breeding season when they need more food.

\section{Prey during breeding and nonbreeding} seasons: Average preying frequency per day was more or less similar during breeding and non-breeding season (Fig. 7). Fish was a preferred targeted during the breeding season but arthropods were favourite food during nonbreeding season. Preying of different food items varied at different day periods during breeding and non-breeding seasons but it was not statistically significant. During breeding season, it preyed on at every hour from 07:01-18:00 $\mathrm{h}$ when they need more food for the rearing of their fledglings while the highest was at 09:01$10: 00 \mathrm{~h}(\mathrm{n}=205)$ but in non-breeding season, it was at 10:01-11:00 h $(\mathrm{n}=202)$ (Fig. 8). The average preying frequency of the food items at different periods during the day (breeding season) was significantly correlated with the average frequency during non-breeding season $(\mathrm{r}$ $=0.55, \mathrm{n}=11, \mathrm{p}<0.05)$. The average preying frequency of fish at different periods during the day (breeding season) was significantly correlated with the average frequency of total food items $(r=0.93, n=11, p<0.05)$ but it was insignificant during non-breeding season $(\mathrm{r}=$ $0.48, \mathrm{n}=9, \mathrm{p}>0.05)$. On the other hand, the average preying frequency of arthropods at different periods (daytime) during breeding 
season was insignificantly correlated with the average frequency of total food items $(r=-0.23$, $\mathrm{n}=11, \mathrm{p}>0.05)$ but it was significant during non-breeding season $(\mathrm{r}=0.48, \mathrm{n}=9, \mathrm{p}<0.01)$. Even the average preying frequency of fish at different periods during the day was not significantly correlated with the average frequency of arthropods during breeding $(\mathrm{r}=$ $0.51, \mathrm{n}=11, \mathrm{p}>0.05)$ and non-breeding season $(\mathrm{r}=0.55, \mathrm{n}=9, \mathrm{p}>0.05)$.

Preying of arthropods during breeding and non-breeding seasons: Average preying frequency of arthropods varied per day during breeding and non-breeding seasons but it was not statistically significant. During breeding season, it occasionally preyed on arthropods $(\mathrm{n}=$ 8) which were not supplied to the nestlings but in non-breeding season it was the highest at 10:01-11:00 h (Fig. 9). Arthropods were preyed throughout the non-breeding season (OctoberMarch) where the highest was in the month of January but they were avoided during the breeding season (April-September) (Fig. 5).

Preying on fish during breeding and nonbreeding seasons: The kingfishers preyed on fish during breeding season to save time and energy. Average preying frequency varied at different periods during breeding and nonbreeding seasons (daytime) (Fig. 9), but it was not statistically significant. Fish were preyed on in all the months of non-breeding season (October-March) where the highest was in October but during the breeding season (AprilSeptember) it gradually increased (Fig. 5) because of the continuous demand by the nestlings.

It was found that the kingfishers preyed on a wide variety of arthropods and fish. The preying frequency varied hourly, daily, and monthly. All the preying attempts were not successful. During the rainy season when most of the fish were bred or at dawn when the insects were active, preying attempts were more successful. The success was more or less dependent on the availability of food items. The food preference was also dependent on the availability and varied during the breeding and non-breeding season. During breeding season the preying frequency was higher because they had to raise the nestlings. Even during breeding, they preferred to prey on fish because the nestlings preferred them. It is not possible to fulfil their great demand by preying on a very small sized arthropods and it is not possible to get a long leisure time for preying a large quantity of arthropods during breeding season. They are beneficial to the aquatic environment as they preyed on comparatively weaker and diseased fish. Thus, necessary conservation measures have to be initiated to conserve the common kingfisher population.

\section{Acknowledgements}

I am grateful to the Ministry of Science, Information and Communication Technology for funding the research. I thank Tauhid Uddin Ahmed for constructive comments to enrich this manuscript and for identifying the arthropods; M. Farid Ahsan for his support, advice, critical comments, and co-operation during the research; and Michael Wasserman (Stedward's University, USA) for reviewing the manuscript.

\section{Literature cited}

Ahsan, M. F. and M. A. Saeed, 1990. Food and feeding habits of some piscivorous birds of Chittagong. Journal of the Asiatic Society of Bangladesh, 16: 39-45.

Ali, S. and S. D. Ripley, 1983. Handbook of the birds of India and Pakistan. Vol. 4. Oxford University Press, New York: 265.

Ali, A. M. S., S. Asokan, and R. Manikannan, 2010. Habitat-related Density and Activity Patterns of the White-breasted Kingfisher Halcyon smyrnensis in Cauvery Delta, Southern India. Podoces, 5: 54-62.

Altmann, J., 1974. Observational study of behaviour: sampling methods. Behaviour, 49: 227267.

Asokan, S., 1995. Ecology of the Small Green Bee-eater, Merops orientalis Latham 1801 with special reference to its population, feeding and breeding in Mayiladuthurai. Tamil Nadu, South India. Ph.D. Thesis, Bharathidasan University, Thiruchirappali, India.

Asokan, S., A. M. S. Ali, and R. Manikannan, 2009. Diet of three insectivorous birds in Nagapattinam District, Tamil Nadu, India - a preliminary study. Journal of Threatened Taxa, 1: 27-33. 
Dhindsa, M. S. and H. K. Saini, 1994. Agricultural ornithology: an Indian perspective. Journal of Bioscience, 19: 391-402.

Evers, D. C., 1994. Activity budgets of a marked common loon (Gavia immer) nesting population. Hydrobiology, 279-280: 415-420.

Heneberg, P., 2004. Soil particle composition of Eurasian Kingfishers' (Alcedo atthis) nest sites. Acta Zoologica. Academiae Scientiarum Hungaricae, 50: 185-193.

Husain, K. Z., 1979. Birds of Bangladesh. Eden press, Dhaka, Bangladesh: 84.

Husain, K. Z., S. U. Sarker and M. M. Rahman, 1983. Summer birds of the Sundarbans Nilkamal Sanctuary, Bangladesh. Bangladesh Journal of Zoology, 11: 48-51.

Islam, M. A., 2003. Kingfisher. In: Islam, S., S. Miah, W. Ahmed, A. M. Chowdhury, S. M. M. Rahman, K. Siddiqui and S. M. H. Kabir, (Ed.). Banglapedia. National Encyclopedia of Bangladesh. Vol. 6. Asiatic Society of Bangladesh, Dhaka: 110-112.

Islam, M. A., M. M. H. Khan, M. M. Kabir, T. Solhoy, N. B. Jordar and M. M. Feeroz, 1999. Winter birds of the Sundarbans, Bangladesh. Ecoprint, 6: 41-49.

IUCN, Bangladesh, 2000. Red Book of Threatened Birds of Bangladesh. IUCN - The World Conservation Union. Dhaka: 116.

Kasahara, S. and K. Katoh, 2008. Food-niche differentiation in sympatric species of Kingfishers, the common kingfisher Alcedo atthis and the greater pied kingfisher Ceryle lugubris. Ornithological Science, 7: 123-134.

Kelly, J. F., 1998. Behaviour and energy budgets of Belted Kingfishers in winter. Journal of Field Ornithology, 69: 75-84.

Khan, M. A. R., 1982. Wildlife of Bangladesh: a checklist. University of Dhaka, Dhaka, Bangladesh: 80.

Khan, M. A. R., 1986. Wildlife in Bangladesh mangrove ecosystem. Journal of Bombay Natural History Society, 83: 32-40.
Melo, M. and J. Fuchs, 2008. Phylogenetic relationships of the Gulf of Guinea Kingfisher. Ibis, 150: 633-639.

Natarajan, V., 1991. Time budgeting by the Southern Crow-pheasant (Centropus sinensis parroti) at Point Calimere, Tamil Nadu. Journal of Bombay Natural History Society, 90: 92-95.

Peris, S. J. and R. Rodriguez, 1997. A survey of the Eurasian Kingfisher (Alcedo atthis) and its relationship with watercourses quality. Folia Zoology, 46: 33-42.

Ramachandran, N. K., 1998. Activity patterns and time budgets of the Pheasant-tailed (Hydrophaslanus chirurgus) and Bronzewinged (Metopidius indicus) Jacanus. Journal of Bombay Natural History Society, 95: 234-245.

Raven, P., 1986. The size of minnow prey in the diet of young Kingfishers, Alcedo atthis. Bird Study, 33: 6-11.

Reza, A. H. M. A., M. M. Ferooz, M. A. Islam, and M. M. Kabir, 2003. Status and density of Kingfishers (Family: Alcedinidae, Halcyonidae and Cerylidae) in the Sunderbans mangroves forest, Bangladesh. Bangladesh Journal of Life Science, 15: 55-60.

Reynolds, S. J. and M. D. C. Hinge, 1996. Foods brought to the nest by breeding Kingfishers Alcedo atthis in the New Forest of southern England. Bird Study, 43: 96-102.

Rodway, M. S., 1998. Activity patterns, diet and feeding efficiency of Harlequin Ducks breeding in northern Labrador. Canadian Journal of Zoology, 76: 902-909.

Sarker, S. U., 1985. Density, productivity and biomass of raptorial birds of the Sunderbans, Bangladesh. Proceeding, SAARC Seminar, Biomass Production. Dhaka. Bangladesh.

Sarker, S. U., 1986. Management of the wildlife of the Sundarbans. Paper presented at the International Seminar-cum-workshop on wildlife conservation in Bangladesh, Dhaka, Bangladesh.

Sarker, S. U., 1989. Fish eating wildlife and some fish of the Sundarbans, Bangladesh. The Journal of Noami, 6: 17-29. 
Sarker, S. U. and N. J. Sarker, 1988. Wildlife of Bangladesh (A systematic list with status, distribution and habitat). Rico Printers, Dhaka: 59.

Sayako, N., K. S. A. Tatsuhiko and K. Ryozo, 2002. Breeding status of common kingfishers Alcedo atthis in the Imperial Palace Ground and the Akasaka Imperial Grounds. Journal of Yamashina Institute for Ornithology, 34: 112-125.

Sibley, C. G. and B. L. Monroe Jr, 1993. A world checklist of birds. Yale University Press, New Haven and London. Checklist available at <www.ces.iisc.ernet.in/hpg/envis/sibleydoc63.htm $>$ access 15 October 2007.

Siddiqui, K. U., M. A. Islam, S. M. H. Kabir, M. Ahmad, A. T. A Ahmed, A. K. M. Rahman, E. U. Haque, Z. U. Ahmed, Z. N. T., Begum, M. A. Hassan, M. Khondker, and M. M. Rahman, (Eds.). 2008. Encyclopedia of Flora and Fauna of Bangladesh. Vol. 26. Birds. Asiatic Society of Bangladesh, Dhaka: 662.

Sivakumaran, N. and K. Thiyagesan, 2003. Population, diurnal activity patterns and feeding ecology of the Indian Roller (Coracias benghalensis). Zoo's Print Journal, 18: 10911095. 


\section{PLATE 9}

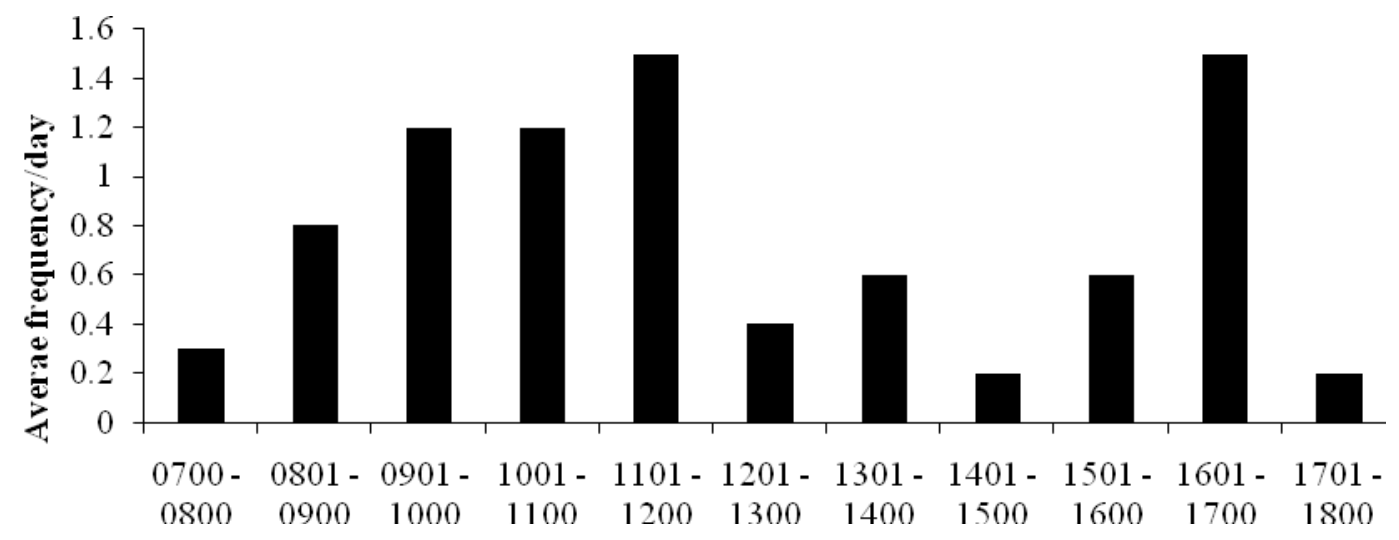

Figure 1: Preying frequency of common kingfisher recorded during various hours of a day.

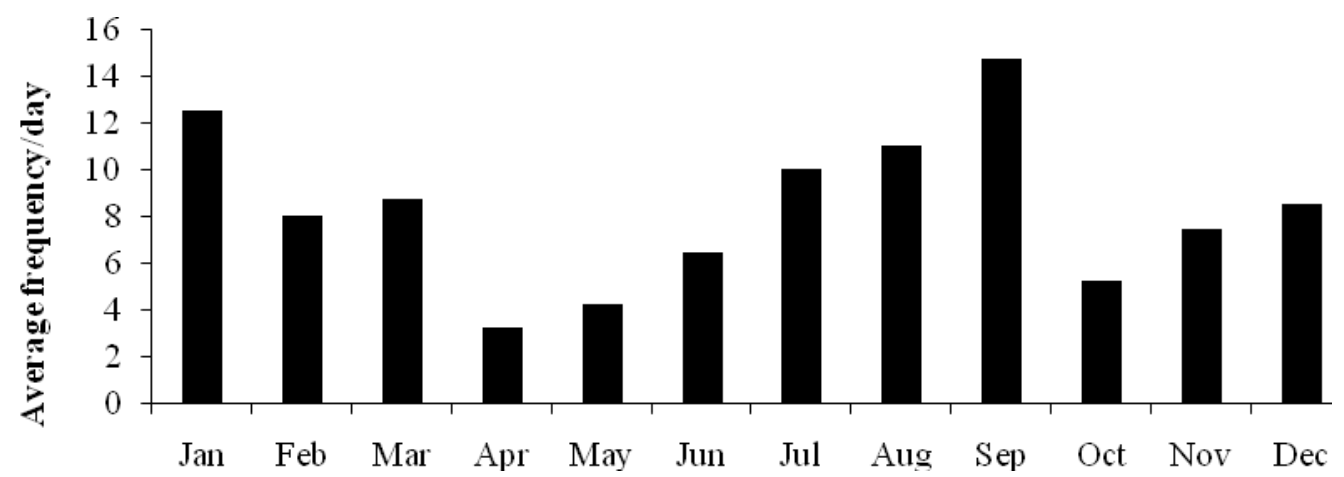

Figure 2: Monthly preying frequency of common kingfisher.

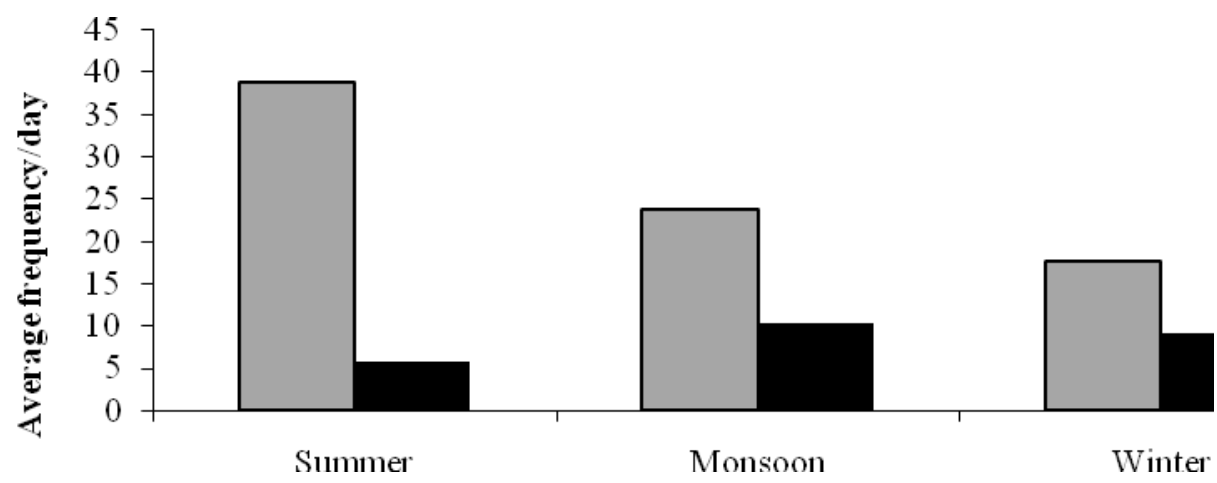

Figure 3: Preying frequency of common kingfisher in different seasons (dark shade, average successful preying frequency; gray shade, average unsuccessful preying frequency) 


\section{PLATE 10}

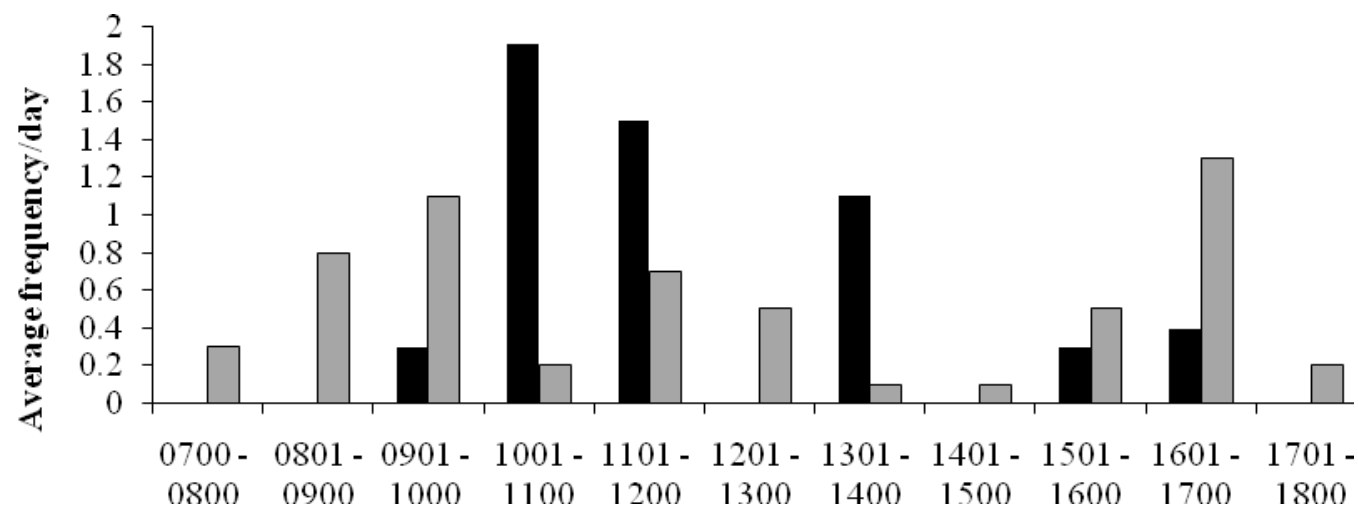

Figure 4: Frequency of prey attempts on arthropods (dark shade) and fishes (gray shade) made by Common Kingfisher during various hours.

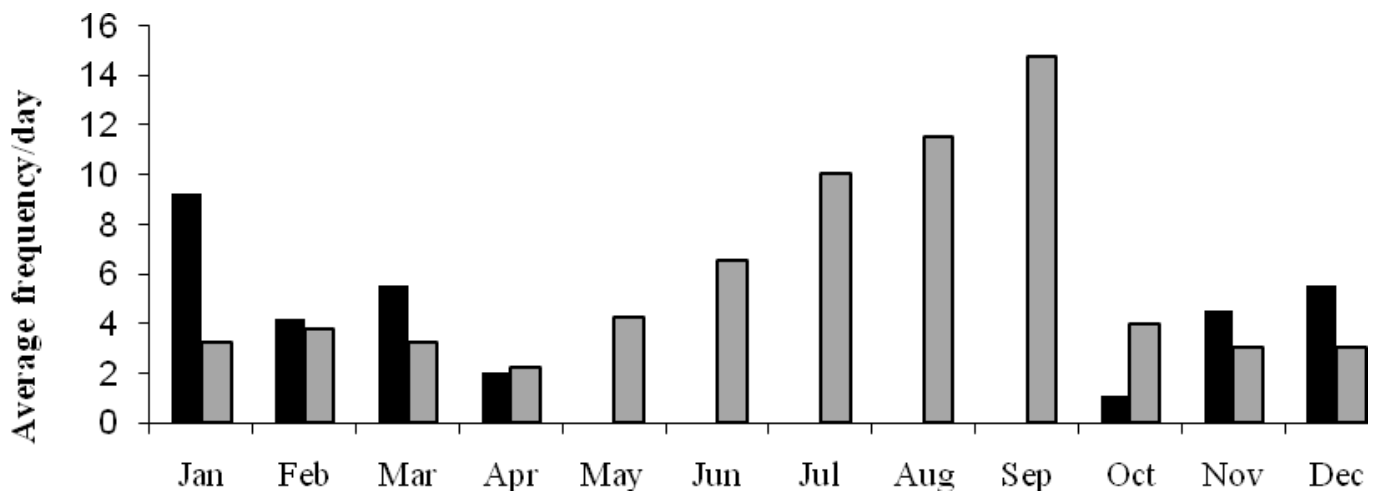

Figure 5: Frequency of prey attempts on arthropods (dark shade) and fishes (gray shade) made by common kingfisher during various months.

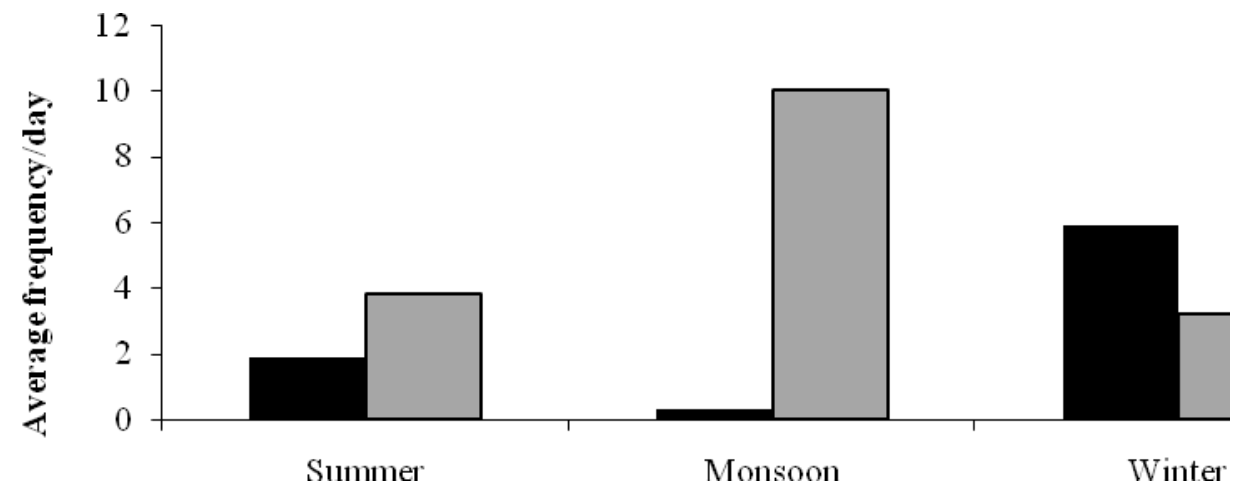

Figure 6: Frequency of prey attempts on arthropods (dark shade) and fishes (gray shade) made by common kingfisher during various seasons. 


\section{PLATE 11}

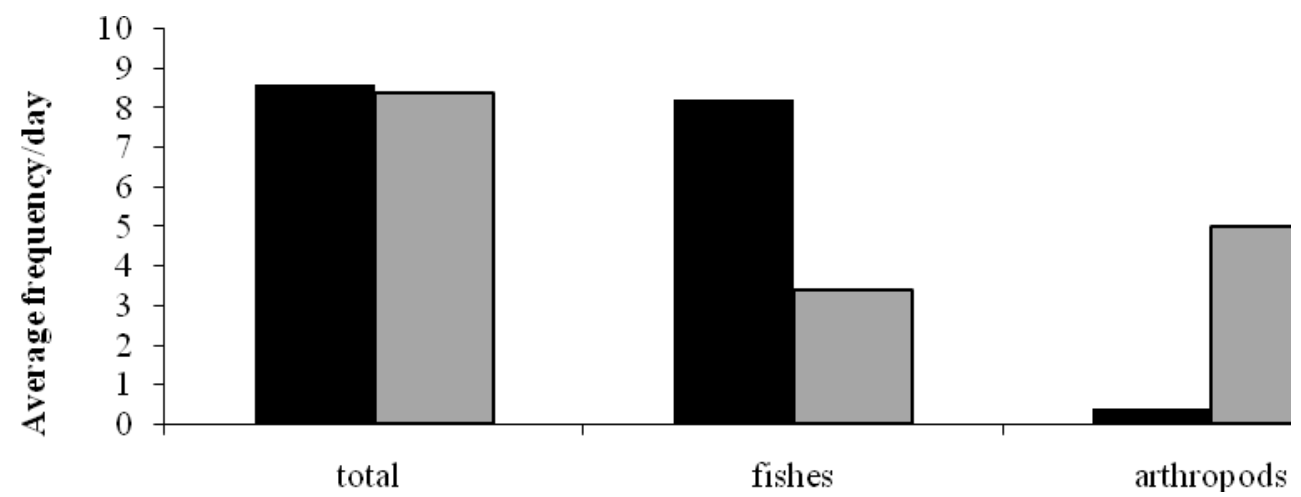

Figure 7: Average preying frequency/day of common kingfisher during breeding (black) and non breeding (gray) seasons.

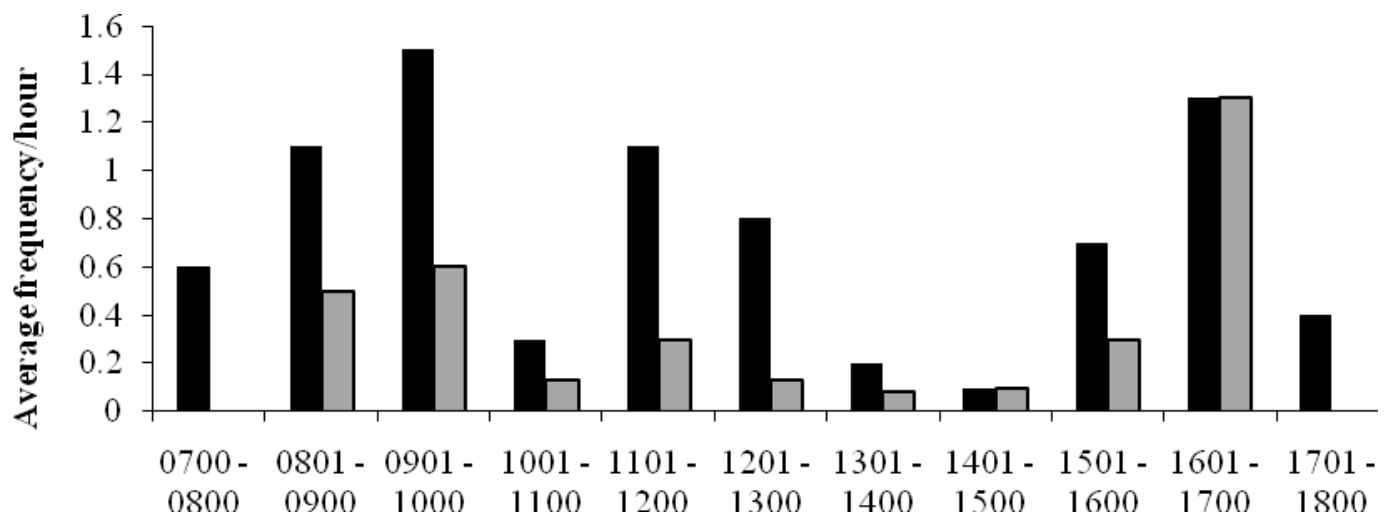

Figure 8: Preying frequency of common Kingfisher in various hours during breeding (black) and non breeding (gray) seasons.

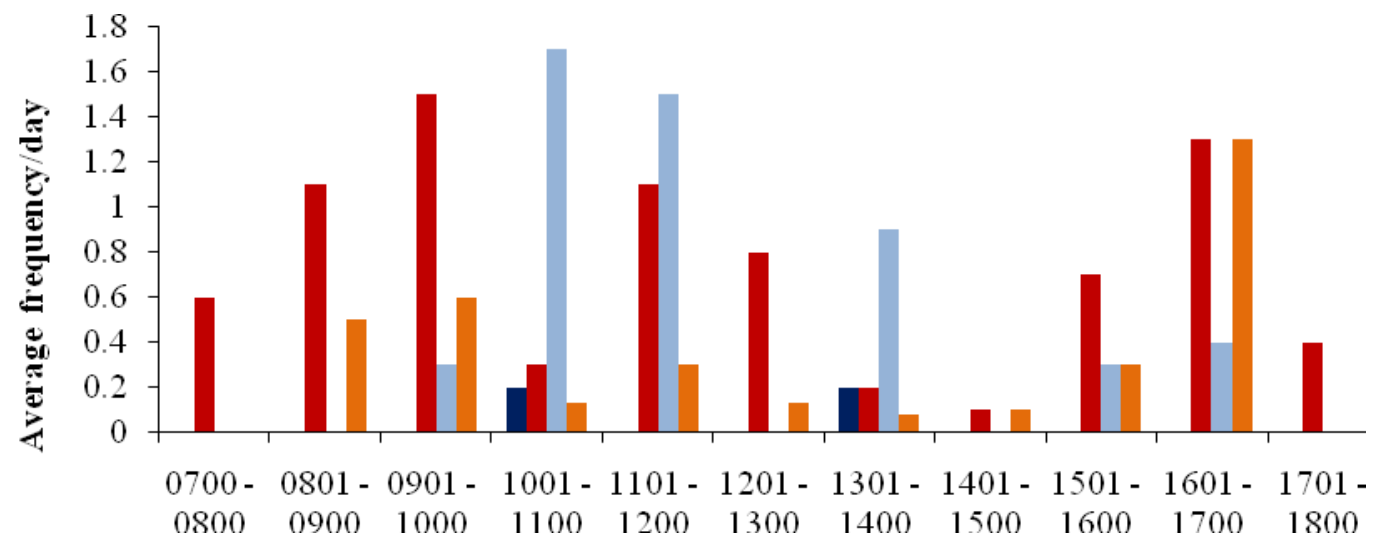

Figure 9: Frequency of prey attempts on arthropods and fishes made by common kingfisher at various hours during breeding and non breeding seasons: Arthropods during breeding (red) and non breeding (orange); fish in breeding (dark blue) and non breeding (light blue). 